This Council will become a permanent Latin American Council once the necessary official steps have been taken throughout all the Latin American countries; the secretariat will be located at the Unesco Science Co-operation Office for Latin America, Bulevar Artigas 1320, Montevideo, Uruguay.

(2) The commencement of research programmes on a regional co-ordinated basis. Seven projects were presented, and the necessary measures are being taken at the present moment for the co-ordination of more than one, in which the existing marine biology laboratories and occanographic institutes will integrate a close network with the help of the means that the hydrographic naval services may provide.

(3) The publication of a Latin American Directory of Oceanographic Institutions and Scientists so as to increase and encourage the exchango of scientists, students, information and material, with the Unesco Science Co-operation Offico acting as a clearing house'.

(4) The unification and standardization of methods and equipment in marine rosearch.

(5) Unesco was asked to organize in 1962 a twomonths' training course in physical oceanography. The Oceanographic Institute of the University of Oriente (Venezuela) extended an invitation to act as host, and the Brazilian Navy offered its oceanographic vessel, Almirante Saldanha, to make a training eruise as a complement of the course.
(6) Uncsco was asked to organize in 1962 a regional Symposium on Biogeography and Marine Organisms, so as to study the geographical distribution of marine organisms and the effects on them, of the physicochemical condition of water masses, and its dynamics. The National Museum of Natural History "Bernardino Rivadavia" (Argentina) made an official invitation to act as host during the celebration of its one hundred and sixtieth anniversary.

(7) Unesco was asked to organize in 1962 a mecting of deans of science faculties of Latin American Universities, so as to increase the scholastic standards needed for the encouragement of marine scientists through the re-organization and modification of their curricula and plans of study.

Preparations for the organization of the last three items have already been started by Unesco Science Co-operation Office. In an effort to compile bibliographies of research work carried out in Latin America on the marine sciences, which already begins to show profitable results, each scientist presont at the mecting will be contributing in his own specific field. To help this aspect of the marine sciences in Latin America, the Council requests all scientists and institutions to send copies of reprints to the Unesco Science Co-oporation Office for Latin America, Casilla de Correo 859, Montevideo, Uruguay, whenever they deal with any aspect of the marine sciences in Latin America.

\title{
CHEMICAL APPLICATIONS OF DIFFRACTION METHODS
}

T $\mathbf{T}$ is nearly fifty years since von Laue, Friedrich and Knipping first diffracted X-rays from a crystal. Since then, diffraction methods, based on X-rays or on analogous but less widely used techniques, have been applied to the investigation of a variety of chemical problems. The scope of these was the subject of a short course of lectures and discussions under the title "Chemical Applications of Diffraction Methods" held in the Department of Chemical Technology, Bradford Institute of Technology, during November 24-25, 1961. About forty graduates from industry, the universities and technical colleges attended.

Participants were welcomed by the head of the Department, Dr. R. L. Elliott, who took the chair for the opening session. In his introductory talk on symmetry and diffraction, Dr. J. H. Robertson (University of Leeds) presented the concept of symmetry in an informal way, in terms of familiar everyday objects, before outlining the types of symmetry appropriate respectively to the external and internal form of erystals. After giving a more formal treatment of the diffraction process, Dr. Robertson showed that, while knowledge of crystal symmetry alone can sometimes yield molecular information directly, it is commonly a preliminary to more detailed $\mathrm{X}$-ray crystal analysis. This was the subject of the talk by Dr. D. W. Jones (Bradford Institute of Technology), who examined the experimental X-ray data available from singlo crystals and stressed the phase problem intrinsic in structure analysis. Tho isomorphous salt and heavy-atom methods of tackling this wore illustrated by the closely related structures of the alkali motal aminedisul phonates; detailed X-ray refinement of the ealcium orthophosphate structures demonstrated the difficulty of locating hydrogen directly in the presence of heavier atoms. Often, however, the approximate stereochemistry of a molecule could be established on the basis of photographic X-ray data alone and without recourse to large-scale computing. The idealized single crystal X-ray analysis method had links, on one hand, with the study of less well-ordered samples by X-rays and, on the other, with diffraction by electrons and neutrons.

The second session was dovoted to more specialized applications of X-ray diffraction. In his talk on fibre crystallography and X-ray crystallinity, Dr. D. R. Holmes (Central Electricity Research Laboratories, Leatherhead) recommended the use, where feasible, of doubly oriented specimens, the tilted 'crystal' method, equi-inclination photography and cylindrical cameras in order to minimize the effect of the paucity of wide-angle $\mathrm{X}$-ray data available from a fibre. Even so, the agreoment between sets of X-ray intensities measurod by different workers for cellulose, for example, was somewhat disappointing. The fairly complete molecular model that can result from the study of well-ordered polymors was illustrated by the structures of silk and polyethylene terephthalate. For the measurement of X-ray crystallinity, however, the oriontation occurring in many industrial fibres could be a handicap, and Dr. Holmes mentioned a device for mechanical random. ization about two axes. Because of its ready application to short-term industrial problems, the X-ray powder method is probably the most widely used diffraction procedure in applied chemistry and metallurgy. Dr. K. W. Andrews (United Steel Companies, Ltd., Rotherham) described experimental techniques 
for such polycrystalline materials and mentioned the increasing importance of automatic counter recording. Powder diagrams were shown to illustrate the identification of metals, alloys and slags with regard to chemical nature (fingerprinting), physical texture, and particle size.

The last session dealt with diffraction of radiation other than X-rays. Dr. H. Wilman (Imperial College of Science and Technology) described the--sometimes rather ad hoc-apparatus used for observing the very intense scattering of electrons and illustrated the range of patterns which may arise. After mentioning the fairly complete structural information which has been obtained from some rubbers and from single crystals, Dr. Wilman discussed recent electron diffraction studies carried out at the Imperial College of Science and Technology on reactions at surfaces. Much of the discussion which followed was concerned with deriving information of use to metallurgists about surface structure.
In the final talk, on neutron diffraction applications, Mr. N. A. Curry (Atomic Energy Research Establishment, Harwell) pointed out that typically a neutron beam would have an effective intensity less than onethousandth of that from an X-ray diffraction source, and, moreover, it covered a range of wave-lengths, so that at most reactors both apparatus and specimen had to be large by standards normally used with $\mathrm{X}$-ray techniques. The markedly different scattering power of nuclei to neutrons (only elastic scattering was considered in any detail), as compared with the corresponding $\mathrm{X}$-ray atomic scattering factors, was the basis of the chief merit of neutron diffraction. In particular (and the subsequent lively discussion centred on this), hydrogen atoms had been located with a precision of $0.03 \AA$. in compounds containing atoms of appreciable atomic number, for example, in the study of the symmetry of short $\mathrm{O}-\mathrm{H} \ldots \mathrm{O}$ bonds in potassium hydrogen bis-phenylacetate.

D. W. JoNES

\section{PLANT TISSUE AND ORGAN CULTURE}

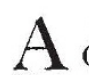

SYMPOSIUM on "Plant Tissue and Organ Culture" was held in the Department of Botany, University of Delhi, during December 22-29, under the auspices of the Unesco South Asia Science Cooperation Office, New Delhi, and the University of Delhi. Prof. P. Maheshwari was the convener. Fifty delegates from Burma, Ceylon, France, West Germany, India, Malaya, the United Kingdom and the United States participated.

The 36 papers presented covered a wide range of subjects, and they show the diversity of purposes for which the technique of plant tissue culture can be used. Quite a few of the papers were concerned with the broad subject of physiology of reproductive processes in angiosperms and involved the culturing of flowers, ovaries, ovules, anthers, etc.

The tissue eulture technique has contributed in recent years to a better understanding of a variety of morphogenetic problems and naturally this aspect found a fair representation at the symposium. The culturing of parts of parasitic higher plants is of special interest from the physiological point of view and there were three papers on this subject.

Embryos are among the material most often used for in vitro culture for a long time, and interest in them still continues as can be seen from the three papers dealing with this means of approach.

Some investigators are interested in tissue culture techniques as an aid in propagation of horticultural plants as seen in two papers presented. Isolated tissues provide a valuable means for the bioassay of growth substances and cell division factors, and several authors described their investigations along these lines.

Studies of abnormal growth might sometimes lead to an elucidation of normal growth processes besides throwing light on the nature of carcinogenic growth in general. From this point of view one paper was of interest.

Knowledge of the nutrition of tissue cultures is of basic importance for the successful growth of tissue cultures of all types, especially since many tissues seem to have certain specific nutritional requirements. This was indicated in three papers. Other aspects of tissue culture methods were dealt with by still further authors.

In addition to the special papers read, a few special lectures were also arranged. Prof. F. C. Steward (Cornell), in his lecture entitled "Carrots and Coconuts: Some Investigations on Growth", dealt at length with the importance of coconut milk and other growth factors with special reference to his own recent work on the culturing of cell suspensions of carrot and of Haplopappus gracilis, the angiosperm with the lowest number of chromosomes $(2 n=4)$. Prof. H. E. Street (Swansea) gave two lectures, both concerned with root growth. In the first he summarized the work done by himself and his coworkers on the role of various sugars, nitrogen sources and other nutritional factors in root cultures. The second gave an exposition of the rather tricky question of the part played by auxins in root growth, tracing the history of the subject with special emphasis on the work done in Prof. Street's labora. tory. Prof. J. Reinert (Berlin-Dahlem) described the formation of adventive embryos and pro-embryolike structures in carrot cultures grown on a purely synthetic medium containing vitamins, amino-acids and hypoxanthine. The differentiation of shoots could be prevented by addition of coconut milk to the medium. Prof. J. P. Nitsch (Gif-sur-Yvette), who was one of the earliest to culture successfully isolated ovaries and flowers of higher plants in vitro, gave an account of some of his recent experiments at the phytotron, France, on the in vitro culture of flowers and fruits of tomato and other plants. Prof. P. Maheshwari (Delhi) spoke on "Plant Tissue and Organ Culture from an Embryologist's Point of View".

The symposium concluded with a discussion on "Techniques: Appraisal of Progress and Future Outlook on Tissue Culture Research" in which several participants expressed the view that in future there should be more emphasis on the biochemical fate of the various growth substances added to the medium and the cytological phenomena accompanying growth of tissue cultures.

R. L. N. SASTRI 